\title{
Optimising Industrial Hemp Fibre for Composites
}

\author{
K.L. Pickering1 ${ }^{*}$, G.W. Beckermann ${ }^{1}$, S.N. Alam ${ }^{1}$ and N.J. Foreman ${ }^{2}$ \\ ${ }^{1}$ Department of Materials and Process Engineering,
}

University of Waikato Private Bag 3105, New Zealand.

${ }^{2}$ Managing Director, Hemptech, Industrial Research Park, Ruakura Rd, Hamilton, New Zealand

\section{ABSTRACT}

The optimisation of New Zealand grown hemp fibre for inclusion in composites has been investigated.

The optimum growing period was found to be 114 days, producing fibres with an average tensile strength of $857 \mathrm{MPa}$ and a Young’s modulus of $58 \mathrm{GPa}$. An alkali treatment with $10 \mathrm{wt} \% \mathrm{NaOH}$ solution at a maximum processing temperature of $160^{\circ} \mathrm{C}$ with a hold time of 45 minutes was found to produce strong fibres with a low lignin content and good fibre separation. Although a good fit with the Weibull distribution function was obtained for single fibre strength, this did not allow for accurate scaling to strengths at different lengths. Alkali treated fibres, polypropylene and a maleated polypropylene (MAPP) coupling agent were compounded in a twin-screw extruder, and injection moulded into composite tensile test specimens. The strongest composite consisted of polypropylene with $40 \mathrm{wt} \%$ fibre and $3 \mathrm{wt} \%$ MAPP, and had a tensile strength of 47.2 MPa, and a Young's modulus of 4.88 GPa.

Keywords: A Natural fibres, A Interface/Interphase, E Injection Moulding *Corresponding author. Tel.: +64 7838 4672, fax.: +64 7838 4835. E-mail: klp@waikato.ac.nz 


\section{INTRODUCTION}

Industrial hemp fibre is one of the strongest and stiffest available natural fibres [1] and therefore has great potential for use in composite materials. The automotive industry has led the way in adopting this fibre in composite materials. In Europe, the up-take of natural fibres in the automotive market has accelerated from 400 tonnes in 1996 to 17,140 tonnes in 2000, predicted to increase to 60,000 tonnes in 2005, with the greatest increases for hemp fibre [2]. However, as a crop-based material, its properties depend on growing conditions, including growth duration and procedures involved to extract the fibre from the plant. Although acceptable composite properties have been obtained from mechanically extracted fibre [3], concern over long term stability due to degradation of lignin [4], which mainly acts as an adhesive holding the cellulose fibres together, suggests that for many applications, it may be best to further process the fibres to remove the lignin before inclusion into composites. Removal of lignin, pectin and hemicellulose by means of alkali treatment has also been shown to improve instantaneous fibre properties due to better packing and increased molecular orientation of cellulose chains [5]. However, overtreatment with alkali has been shown to reduce fibre properties [6]. Therefore in order to optimise composite strength, it is important to be able to assess the effect of fibre extraction as well as growing conditions on fibre properties, particularly fibre strength.

Information available on the effect of growing conditions and extraction on the strength of individual hemp fibres is limited. A major factor here is that single fibre testing is an involved and time-consuming process. Strength values quoted for hemp fibre are commonly based on yarn or fibre bundle strength [7- 
12] or of unspecified origin [13-15]. Where single fibre strengths for hemp are described, these have been carried out at different gauge lengths $[16,17]$ or unspecified gauge lengths [14]. Testing by Snell et al. [16] was carried out for instance with gauge lengths of approximately $1 \mathrm{~mm}$ whereas single hemp fibres were tested at gauge lengths of $10 \mathrm{~mm}$ by Beckermann et al. [17]. However, the strength of natural fibres including flax, hemp and sisal has been shown, not surprisingly for materials which undergo little plastic deformation and, therefore, are likely to have their strength dictated by the defects present, to depend on fibre length $[8,18]$ as is the case for brittle synthetic fibres [19]. Therefore, for comparison purposes, it would be useful to be able to scale the strength measured at one length to predict what it would be at a different gauge length. In addition, the ability to predict the strength of very short lengths of fibre is important in models for composite strength [20].

The ability to scale fibre strengths at one length to predict the strength at a different length is incorporated within the two parameter Weibull equation [21] as shown below:

$$
P_{f(L)}=1-\exp \left[-L\left(\frac{\sigma}{\sigma_{0}}\right)^{w}\right]
$$

where $\mathrm{P}_{f(L)}$ is the probability of failure of a fibre of length $L$ at a stress less than or equal to $\sigma, \sigma_{0}$ is the Weibull scale parameter or characteristic stress, and w is the shape parameter or Weibull modulus which describes the variability of the failure strength. This is commonly used to describe fibre strength distributions for brittle fibres and has been shown to give a reasonable fit to fibre strength at a single gauge length for natural fibres [22]. Rearrangement of the two-parameter Weibull cumulative distribution expression (equation 1) gives the following:

$$
\ln \ln \left(\frac{1}{1-P_{f}}\right)=w \ln \sigma-w \ln \sigma_{0}+\ln L
$$


and hence the scale and shape parameters can be obtained from a plot of $\ln \ln \left(1 / 1-\mathrm{P}_{f}\right)$ versus $\ln \sigma$ (commonly referred to as a Weibull plot) which should produce a straight line, with gradient $\mathrm{w}$ and intercept $\sigma_{0}$ at $\ln \ln \left(1 / 1-\mathrm{P}_{f}\right)=0$.

A fibre can be considered as made up of segments or 'links', each containing a flaw of varying severity [21]. Therefore, the fibre can be considered to have failed if one of its links has failed. This type of model is referred to as the 'Chain of Links' model. A longer fibre can be considered to have a larger number of links than a shorter one and therefore, there is an increased probability of encountering a more severe flaw along the fibre length. Hence, longer fibres, as observed, would be expected to have on average a lower strength than shorter fibres. As a consequence of the form of the Weibull equation (Equation 1), values of strength obtained at any given gauge length may be used to predict the strength of a fibre for another length, for a similar probability of failure by means of the following equation:

$\sigma_{0(2)}=\sigma_{0(1)}\left(\frac{\mathrm{L}_{1}}{\mathrm{~L}_{2}}\right)^{1 / w}$

where $\sigma_{0(2)}$ and $\sigma_{0(1)}$ are the strengths for lengths $\mathrm{L}_{2}$ and $\mathrm{L}_{1}$ respectively. This is the principle of 'weak-link scaling'. A plot of the logarithm of characteristic strength versus the logarithm of length should give a straight line if weak link scaling is observed, from which the Weibull modulus can be obtained from the reciprocal of the gradient.

In the current work, an investigation has been performed on a trial crop of New Zealand grown hemp to assess the effects of growth time and digestion parameters for optimising the production of hemp fibre for composite materials. The suitability of using Weibull statistics for scaling values of strength obtained at a 
given gauge length to predict the strength at a different gauge length and prediction of composite properties has been assessed.

\section{MATERIALS}

Two sources of New Zealand grown industrial hemp (Cannabis sativa L.) were used in this investigation: (1) semi-retted hemp stalks grown in the Hawkes Bay region, and (2) hemp stalks grown in the Waikato region (supplied by Hemptech NZ Ltd.). Analytical grade sodium hydroxide pellets (98\% purity) were used in the alkali treatment of the fibres. The following general laboratory reagents were used to determine the lignin content of the alkali treated fibres: potassium permanganate $\left(\mathrm{KMnO}_{4}\right)$ solution standardised to $0.02 \mathrm{M} \pm 0.0001 \mathrm{M}$; sodium thiosulphate $\left(\mathrm{Na}_{2} \mathrm{~S}_{2} \mathrm{O}_{3}\right)$ solution standardised to $0.2 \mathrm{M} \pm$ 0.0005M; $1 \mathrm{M}$ potassium iodide (KI) solution; $10 \%$ potassium iodide (KI) solution; $2 \mathrm{M}$ sulphuric acid $\left(\mathrm{H}_{2} \mathrm{SO}_{4}\right) ; 2 \%$ starch indicator solution; and a $0.0167 \mathrm{M}$ potassium iodate $\left(\mathrm{KIO}_{3}\right)$ solution. Polypropylene (Icorene ${ }^{\circledR}$ PP CO14RM) was used as the composite matrix; and A-C 950P high molecular weight MAPP, supplied by Honeywell International Inc, USA, was used as the coupling agent.

\section{EXPERIMENTAL}

\subsection{Hemp Plant Growth and Harvesting}

A stand of industrial hemp was grown in the Waikato region of New Zealand from mid October 2002.

When the male plants were about to start releasing pollen (99 days after planting), several plants were harvested for fibre strength analysis. After that, plants were harvested at 5-day intervals, with the final 
harvest taking place 124 days after sowing. The hemp stalks were then water-retted for 6 days to separate the strong outer bast fibres from the woody core, as well as to separate the individual fibres from their fibre bundles. Retting is a controlled bio-degradation of the hemp stem, which breaks down the hemicellulose and pectin holding the individual fibres together. After retting, the fibres were dried at $80^{\circ} \mathrm{C}$ for 24 hours.

\subsection{Alkali Treatment of Hemp Fibre}

Hawkes Bay grown hemp was scutched to remove the bast fibres from the woody core, and the bast fibre tissue was chopped into lengths of approximately $10 \mathrm{~cm}$. Small quantities of fibre were then weighed and placed in 1 litre stainless steel canisters with a pre-mixed $\mathrm{NaOH}$ solution such that the fibre: $\mathrm{NaOH}$ solution ratio was 1:6 by weight. The canisters were then inserted into a small lab-scale pulp digester for alkali treatment, and the predetermined treatment cycles were controlled by a 10-step PLC program. The following treatment variables were manipulated for the different alkali treatments, as can be seen in Figure 1:

(1) $\mathrm{NaOH}$ concentration: $10 \mathrm{wt} \%$ or $15 \mathrm{wt} \% \mathrm{NaOH}$ solutions (by weight),

(2) Treatment temperature: $160^{\circ} \mathrm{C}$ or $180^{\circ} \mathrm{C}$,

(3) Hold time at the maximum temperature: 15 minutes or 45 minutes.

After treatment, the fibres were thoroughly washed for 10 minutes using a pulp and paper fibre-washer.

Fibres were then dried at $80^{\circ} \mathrm{C}$ for 48 hours.

The surfaces of untreated and alkali treated fibres were observed using a Scanning Electron Microscope (SEM). 


\section{$\underline{\text { 3.3 Mechanical Testing of Single Hemp Fibres }}$}

The tensile testing of the retted single hemp fibres was based on the ASTM D3379-75 Standard Test Method for Tensile Strength and Young's Modulus for High-Modulus Single Filament Materials. Hemp fibres were separated by hand, and mounted on cardboard mounting-cards with $10 \mathrm{~mm}$ holes punched into them (ie 10mm gauge length). A small amount of PVA glue was applied to the two edges on either side of the hole along the length of the card, and the fibres were carefully put into place. The fibres were then inspected, under an optical microscope with a calibrated eyepiece at 200x magnification, to record the average diameter of each fibre, and to ensure that only a single fibre was present on each card. The mounted single fibres were then individually placed in the grips of an Instron-4204 tensile testing machine, and the supporting sides of the mounting cards were carefully cut using a hot-wire cutter. The fibres were then tensile tested to failure at a rate of $0.5 \mathrm{~mm} / \mathrm{min}$ using a $10 \mathrm{~N}$-load cell. Average strengths were obtained using results from thirty specimens. Single fibre tensile tests were also performed to determine the tensile strength and stiffness of the alkali treated fibres as described previously for retted fibres. Single fibre tensile testing was also carried out at an additional gauge length of $1.5 \mathrm{~mm}$ for the fibre found to have been optimally treated to enable Weibull analysis. The degree of delignification of the alkali treated fibre was determined using the Half-Scale Kappa Test based on the AS/NZS 1301.201s:2002, the Papro 1.106 Kappa Number (Half Scale Modification) and TAPPI T236 Standards.

\section{$\underline{\text { 3.4 X-Ray Diffraction }}$}

Untreated and alkali treated Hawkes Bay hemp fibre (treated with $10 \% \mathrm{NaOH}$ at a maximum temperature of $160^{\circ} \mathrm{C}$ and a hold time of 45 minutes) was chopped into fine particles and compressed into disks using a 
cylindrical steel mould $(\varnothing=15 \mathrm{~mm})$ with an applied pressure of 32 MPa. A Philips X'Pert diffractometer fitted with a ceramic $\mathrm{x}$-ray diffraction tube was used to assess the influence of alkali treatment on fibre crystallinity. The diffracted intensity of CuKa radiation (wavelength of $0.1542 \mathrm{~nm}$ ) was recorded between $5^{0}$ and $40^{\circ}(2 \theta$ angle range $)$ at $40 \mathrm{kV}$ and $40 \mathrm{~mA}$. The crystallinity index $\left(\mathrm{I}_{\mathrm{c}}\right)$ of the fibre was calculated using the following formula [23]:

$I_{c}=\left(\frac{I_{002}-I_{a m}}{I_{002}}\right) \times 100$

where $\mathrm{I}_{002}$ is the maximum intensity of diffraction of the (002) lattice peak at a $2 \theta$ angle of between $22^{\circ}$ and $23^{0}$, and $\mathrm{I}_{\mathrm{am}}$ is the intensity of diffraction of the amorphous material, which is taken at a $2 \theta$ angle between $18^{0}$ and $19^{0}$ where the intensity is at a minimum [24].

\subsection{Composites Fabrication}

Composites were fabricated using Hawkes Bay hemp that had been optimally alkali treated. The fibres were either chopped up into fibre lengths of 1-3mm using an industrial granulator (short fibres), or manually chopped into $10 \mathrm{~mm}$ lengths using a guillotine (long fibres), and then dried at $80^{\circ} \mathrm{C}$ for 48 hours. The polypropylene and the MAPP coupling agent used in the composites were also dried for the same length of time. The hemp fibres, polypropylene and MAPP were then compounded in a ThermoPrism TSE-16-TC twin-screw extruder, such that composites with varying weight fractions of fibre, MAPP and polypropylene were produced. Composites were made using long fibres as well as the short fibres to compare the effects of fibre length on the properties of the composite. The extruded composites were then granulated into pellet form and dried at $80^{\circ} \mathrm{C}$ for 48 hours. The composite pellets were then injection moulded into Type 1 tensile test specimens (as specified by the ASTM D638-01 standard) using a BOY15-S injection-moulding machine. 


\subsection{Tensile Testing of Composites}

Tensile test specimens were placed in a conditioning chamber at $23^{\circ} \mathrm{C} \pm 3^{\circ} \mathrm{C}$ and $50 \% \pm 5 \%$ relative humidity for 40 hours. The specimens were then tested using an Instron-4204 tensile testing machine fitted with a 5kN-load cell, and operating at a rate of 5mm/min. An Instron 2630-112 extensometer was used to measure the strain. The composite specimens were tested to failure, whereas the non-fibre containing specimens were only tested to the point of maximum stress due to excessive necking. Ten specimens were used for each test.

\section{RESULTS AND DISCUSSION}

\subsection{The Effects of Growing Time on Fibre Strength}

The single fibre tensile test results performed on retted Waikato-grown hemp are shown in Figure 1. The error-bars each represent \pm 1 standard deviation. From the results, it can be seen that there is a slight, but statistically significant (assessed by a single tailed student t-test) increase in the average tensile strength of hemp fibre during the growth period from 99 days to 114 days (observed value of $\mathrm{t}=2.96, \mathrm{df}=56$, $\mathrm{p}<0.05$ ). After 99 days of growth, the male plants had started to release their pollen (start of male plant flowering); and by 124 days, about $80 \%$ of the pollen had been released (end of male plant flowering). This increase in the average fibre tensile strength is likely to be due to changes in fibre morphology as reported in the literature by Mediavilla et al. [25] and a change in the type of fibre being produced during the flowering stage. Mediavilla et al. showed that the long, strong primary bast fibres are first created almost empty, and then progressively fill between the vegetative growth and flower formation stages. 
This filling of the primary fibres is thought to increase the average fibre tensile strength. With the introduction of the generative phase (seed production), shorter and weaker secondary fibres are produced in greater numbers, which would be expected to eventually result in a decrease in the average fibre strength (not assessed in the current work). A peak in average fibre strength can then be achieved at a point where the primary fibres have been filled to a large extent, and just before an increase in secondary fibre production commences.

Other possible explanations for the change in fibre strength could be due to the changing chemical composition of bast fibres during the aging of the plant [26]. No further investigation was performed to determine the chemical composition or changes in chemical composition of the fibres. It was also noted that the average unretted fibre strength appeared to be considerably higher than the average strength of the retted fibres. This is could be due to more primary unretted bast fibres being extracted from the bark for tensile testing instead of a random mix of primary and secondary fibres. Primary bast fibres are longer and stronger than secondary fibres and contain less lignin, thus making them easier to extract from the unretted bark.

The shape of the stress-strain curves was found to vary markedly between fibres. The different forms are shown in Figure 2 representing behaviour ranging from strain hardening (a), through linear elastic (b) to the inclusion of some plastic flow (c). For the untreated samples around 64\% demonstrated linear elastic behaviour, 30\% plastic flow and 6\% showed strain hardening behaviour. Variation of behaviour reported elsewhere [18], describes variability of stress-strain behaviour of flax fibres including linear elastic and strain hardening behaviour. 


\subsection{The Effects of Alkali Treatment on Fibre Properties}

From the results in Table 1, it can be seen that each of the three alkali treatment variables had an effect on the tensile strength of the treated fibres. Treatments 1,2 and 4 produced fibres that were stronger than the control (untreated fibres), whereas treatments 3, 5 and 6 resulted in weaker fibres.

The increase in fibre strength for treatments 1, 2, and 4 can be attributed to an increase in packing density and molecular orientation due to the removal of the cementing materials (ie lignin, pectin and hemicellulose) [27]. The decrease in strength for treatments 3, 5 and 6 can be attributed to the degradation of cellulose at temperatures above $160^{\circ} \mathrm{C}$ [28] and at high $\mathrm{NaOH}$ concentrations. It can also be seen that the amount of residual lignin in the fibres, represented by the Kappa number, decreased with an increase in $\mathrm{NaOH}$ concentration, hold time and processing temperature. From the results in Table 1, it can be seen that the most suitable treatment for producing strong, well-separated fibres with low lignin content is treatment 2 .

\subsection{Microscopic Evaluation of Untreated and Alkali Treated Fibres}

The surfaces of untreated and alkali treated Hawkes Bay hemp fibres (treatment 2) were observed using a Scanning Electron Microscope (SEM). An untreated fibre can be seen in Figure 3(a) and an alkali treated fibres can be seen in Figure 3(b). From the SEM micrographs, it can be seen that the gummy polysaccharides of lignin, pectin and hemicellulose are localized on the surfaces of the untreated fibres. In contrast, the alkali treated fibres have much reduced diameters and appear to have clean but rough surfaces with large numbers of etched striations. The rough surface morphology of the alkali treated 
fibres is expected to assist with mechanical interlocking when used in composites, and the clean surfaces are expected to provide direct bonding between the MAPP coupling agent and the microfibril cellulose.

\subsection{Weibull Analysis}

Weibull plots are presented in Figure 4 for hemp treated using treatment 2 at gauge lengths of $1.5 \mathrm{~mm}$ and 10mm. Similarly to the trend seen by Biagotti et al. for flax [22], good agreement with the Weibull distribution is shown by proximity to the straight lines with the worst disparity occurring at the lowest strength values. Weibull moduli of 3.4 and 4.2 were obtained from the gradient of the best fit lines at $1.5 \mathrm{~mm}$ and $10 \mathrm{~mm}$ gauge lengths respectively. These are higher than the Weibull modulus of 2.6 for untreated flax fibre [22] indicating less variability.

The average strengths at different gauge lengths followed the expected trend, with that at $10 \mathrm{~mm}$ (677 MPa), being lower than that at a gauge length of $1.5 \mathrm{~mm}$ (786 MPa). The weak link scaling plot with data points from the 1.5 and $10 \mathrm{~mm}$ gauge length data, as well as the best straight line through these, is shown in Figure 5. The Weibull modulus obtained from this plot was 11.7, so very different to that obtained from the individual gauge length data. Also shown in Figure 5 are extrapolations from $1.5 \mathrm{~mm}$ and $10 \mathrm{~mm}$ data points using the Weibull moduli obtained at their respective gauge lengths. As can be seen, there is significant discrepancy between experimentally obtained values and those obtained by weak link scaling from samples of a different gauge length. The characteristic stress obtained from the $10 \mathrm{~mm}$ gauge length data was $745 \mathrm{MPa}$, however that predicted for a $10 \mathrm{~mm}$ gauge length by weak link scaling the data from the $1.5 \mathrm{~mm}$ gauge length samples was $501 \mathrm{MPa}$. Weak link scaling the data obtained from $10 \mathrm{~mm}$ gauge length data gave a predicted characteristic strength of $1170 \mathrm{MPa}$ at $1.5 \mathrm{~mm}$ compared to $876 \mathrm{MPa}$ 
obtained experimentally at $1.5 \mathrm{~mm}$. The disparity between experimental and predicted values is greater than $30 \%$ in both cases. Therefore, it was assumed that weak link scaling could not be used to scale strength obtained at one length to predict strength at a different gauge length.

\subsection{Determination of the Crystallinity Index by the XRD Technique}

The X-ray diffractograms of untreated and alkali treated hemp fibre can be seen in Figure 6. It can be observed that the major crystalline peak on each pattern occurred at around $2 \theta=22.5^{0}$, which represents the cellulose crystallographic plane (002). The X-ray diffractograms show that the intensity of the (002) crystallographic plane was increased significantly by alkali treatment of the hemp fibre. The crystallinity index of the treated and untreated hemp samples were calculated using Equation 4 which is described in the experimental section, and the results are summarised in Table 2. It can be seen in Table 2 that the crystallinity index of the hemp fibre increased with alkali treatment. This is thought to be due to better packing and stress relaxation of cellulose chains as a result of the removal of pectins and other amorphous constituents from the fibre [29]. The increase in crystallinity obtained by alkali treating the hemp fibre is thought to be the main contributing factor for the increase in fibre strength for treatment no. 2, as seen in Table 1.

Other well defined peaks present on the X-ray diffractograms are at $2 \theta=14.8^{0}$ and $2 \theta=16.4^{0}$, and these reflections correspond with the (110) and (110) crystallographic planes respectively. When the crystalline cellulose content is high, these two peaks are more pronounced, and when the fibre contains large amounts of amorphous material (such as lignin, hemicelluloses, pectins and amorphous cellulose), these two peaks are smeared and appear as one broad peak [23]. It can be seen in Figure 6 that the peaks at 
$14.8^{0}$ and $16.4^{0}$ are more defined for the alkali treated hemp fibre, therefore suggesting that the alkali treatment removed some of the amorphous materials from the fibre.

\subsection{The Effects of MAPP, Fibre Content and Fibre Length on Composite Properties}

The results in Tables 3 and 4 clearly show that an increase in composite strength $(\sigma)$ and stiffness (E) can be gained by increasing the weight fraction of hemp fibre and MAPP coupling agent in the composite.

The strongest composite contained 40wt\% hemp and 3wt $\%$ MAPP and the increases in tensile strength and Young's modulus compared to pure polypropylene were $107 \%$ and 356\% respectively. The hemp fibres that were used had a tensile strength of $677 \mathrm{MPa}$, compared to $22.8 \mathrm{MPa}$ for the polypropylene matrix, so it was expected that an increase in the fibre content would have considerably increased the composite strength. However, due to inefficient adhesion between the fibres and matrix, the tensile strengths of the uncoupled composites were far below their potential values. By adding 3wt\% MAPP, the fibre-matrix interfacial bonding was improved, and a tensile strength increase of $68 \%$ was achieved for the composite containing $40 \mathrm{wt} \%$ fibre. The Young's modulus of this composite was also increased by $31 \%$ with the addition of 3wt $\%$ MAPP.

At $30 \mathrm{wt} \%$ and $40 \mathrm{wt} \%$ fibre contents, the longer fibres provided better composite reinforcement, whereas at 50wt\% fibre, increased frictional forces experienced during composite processing appeared to have damaged the fibres and resulted in reduced mechanical properties. 


\section{CONCLUSIONS}

In this investigation, it was shown that the average tensile strength of hemp bast fibres changed during the flowering stage of the plant, with an increase in strength being observed up to around 114 days of growing. The fibre strength was improved by alkali treatment of the fibre. A treatment using a $10 \mathrm{wt} \%$ $\mathrm{NaOH}$ solution, with a maximum processing temperature of $160^{\circ} \mathrm{C}$ and a maximum temperature hold time of 45 minutes produced the strongest fibres, with a much reduced lignin content and improved fibre separation. This alkali treatment method resulted in fibre with a higher crystallinity index compared to that of untreated fibre, and this is thought to be due to better packing of the cellulose chains with the removal of amorphous materials from the fibre. Although a good fit with the Weibull distribution function was obtained for single fibre strength, this did not allow for accurate scaling to strengths at different lengths. Hemp fibre reinforced polypropylene composites were produced, with the strongest and stiffest composite containing 40wt\% hemp fibre. Further improvements in composite strength and stiffness were achieved by adding MAPP, due to the improved fibre-matrix interfacial bonding. A MAPP content of 3wt\% produced the best results. It was also shown that an increase in reinforcing fibre length could improve the composite strength and stiffness of composites with $30 \mathrm{wt} \%$ or $40 \mathrm{wt} \%$ fibre.

\section{ACKNOWLEDGEMENTS}

The authors would like to acknowledge Technology New Zealand for funding of this work.

\section{REFERENCES}


1. Pickering KL et al. Feasibility Study for NZ Hemp Fibre Composites. Journal of Advanced Materials, 2005;37(3);15-20.

2. Plackett D. The Natural Fiber-Polymer Composite Industry in Europe - Technology and Markets. Progress in Woodfibre-Plastic Composite. Toronto, Canada, 2002.

3. Hepworth DG et al. The Use of Unretted Hemp Fibre in Composite Manufacture. Composites Part A 2000;31:1279-1283.

4. Rowell RM. A New Generation of Composite Materials From Agro-based Fiber. in 3rd international conference on frontiers of polymers and advanced materials. Kuala Lumpar,Malaysia: Plenum Press, New York, 1995.

5. Gassan J and Bledzki AK. Alkali Treatment of Jute Fibers: Relationship between structure and mechanical properties. Journal of Applied Polymer Science 1999;71:623-629.

6. Beg MDH and Pickering KL. Effect of Fibre Pre-Treatment on the Mechanical Properties of Wood/Polypropylene Composites. In: Proceedings of 2nd International conference on Structure, Processing and Properties of Materials. Dhaka, Bangladesh, February, 2004:240-247.

7. McGovern JN. Fibres, Vegetable. In: Othmer K, editor. Encyclopedia of Chemical Technology. 4th ed. Vol. 10, Wiley Interscience, 1980:729-730.

8. Mieck KP, Reussmann T and Nechwatal A. About the Characterization of the Mechanical Properties of Natural Fibres. Mat.-wiss. u. Werkstofftech 2003;34:285-289.

9. Bledzki AK, Fink H-P and Specht K. Unidirectional Hemp and Flax EP- and PP-Composites: Influence of Defined Fiber Treatments. Journal of Applied Polymer Science 2004;93:2150-2156. 
10. Mwaikambo LY and Ansell AP. Hemp Fibre Reinforced Cashew Nut Shell Liquid Composites. Composites Science and Technology 2003;63:1297-1305.

11. Prasad BM and Sain M.M. Mechanical Properties of Thermally Treated Hemp Fibers in Inert Atmosphere for Potential Composite Reinforcement. Mat Res Innovat 2003;7(231):231-238.

12. Lilholt H and Lawther JM. Natural Organic Fibers. In: Zweben C and Kelly A. editors. Comprehensive Composite Materials Vol. 1, Pergamon, 2000:303-325.

13. Beukers A. In: Van Hinte E. editor. Lightness the Inevitable Renaissance of Minimum Energy Structures, Rotterdam: 010 publishers, 1999:72.

14. Robson D and Hague J. A Comparison of Wood and Plant Fiber Properties. In: Proceedings of Woodfiber-plastic Composites Conference. Madison, Wisconsin, 1995:41-46.

15. Wambua P, Ivens J and Verpoest I. Natural Fibres: Can They Replace Glass in Fibre Reinforced Plastics? Composites Science and Technology 2003;63:1259-1264.

16. Snell R, Hague J and Groom L. Characterising Agrofibers for Use in Composite Materials. In: The Fourth International Conference on Woodfiber-Plastic Composites. Madison, Wisconsin, 1993:5-11.

17. Beckermann G, Pickering KL and Foreman NJ. The Processing, Production and Improvement of Hemp-Fibre Reinforced Polypropylene Composites Materials. In: Proceedings of the 2nd International Conference on Structure, Processing and Properties of Materials. Dhaka, Bangladesh. 2004:257-265.

18. Andersons J et al. Strength Distribution of Elementary Flax Fibres. Composites science and technology 2005;65:693-702. 
19. Pickering KL and Murray TL. Weak Link Scaling Analysis of High-Strength Carbon Fibre. Composites Part A 1999;30:1017-1021.

20. Bader MG et al. Failure Micromechanics in Continuous Carbon-Fibre Epoxy-Resin Composites. Composites Science and Technology 1993;48:135-142.

21. Weibull WJ. A Statistical Distribution Function of Wide Applicability. J. Applied Mechanics 1951;18:293-297.

22. Biagiotti J et al. A Systematic Investigation on the Influence of the Chemical Treatment of Natural Fibers on the Properties of Their Polymer Matrix Composites. Polymer Composites 2004;25(5):470-479.

23. Tserki V et al. A Study of the Effect of Acetylation and Propionylation Surface Treatments on Natural Fibres. Composites Part A: Applied Science and Manufacturing 2005; 36(8): 1110-1118

24. Roncero, M.B et al. The Effect of Xylanase on Lignocellulosic Components During the Bleaching of Wood Pulps. Bioresource Technology 2005; 96(1): 21-30

25. Mediavilla V and Leupin M. Influence of the Growth Stages of Industrial Hemp on the Yield Formation in Relation to Certain Fibre Quality Traits. Industrial Crops and Products 2001;13: 49-56.

26. Keller A and Leupin M. Influence of the Growth Stages of Industrial Hemp on Chemical and Physical Properties of Jute/Epoxy Composites by Alkali Treatment of Fibres. Industrial Crops and Products 2001;13:35-48. 
27. Gassan J and Bledzki AK. Possibilities for Improving the Mechanical Properties of Jute/Epoxy Composites by Alkali Treatment of Fibres. Composites Science and Technology 1999. 59(9): 1303-1309.

28. Joseph PV and Joseph K. The Thermal and Crystallisation Studies of Short Sisal Fibre Reinforced Polypropylene Composites. Composites Part A 2003;34(3):253-266.

29. Ouajai S and Shanks RA. Composition, Structure and Thermal Degradation of Hemp Cellulose After Chemical Treatments. Polymer Degradation and Stability, 2005; 89(2):327-335 


\section{Figure Captions:}

Figure 1. The average tensile strength of single hemp fibres over a range of growing periods. All fibres were retted unless otherwise stated.

Figure 2. Typical stress-strain curves for hemp fibres.

Figure 3(a). SEM of untreated hemp fibre surface.

Figure 3(b). SEM of alkali treated hemp fibre surface.

Figure 4. Weibull plots for hemp tested at $1.5 \mathrm{~mm}$ and $10 \mathrm{~mm}$ gauge lengths

Figure 5. Weak link scaling plot showing extrapolated predictions from values at 1.5 and $10 \mathrm{~mm}$ gauge lengths

Figure 6. X-Ray diffraction patterns of $\mathrm{NaOH}$ treated and untreated hemp fibre 
Table 1. Effect of fibre treatment on the tensile strength and lignin content of hemp fibres.

\begin{tabular}{ccccccc}
\hline $\begin{array}{c}\text { Treatment } \\
\text { no. }\end{array}$ & $\begin{array}{c}\text { NaOH } \\
\text { concentration }\end{array}$ & $\begin{array}{c}\text { Max process temp } \\
\left({ }^{\circ} \mathbf{C}\right)\end{array}$ & $\begin{array}{c}\text { Hold time } \\
(\mathbf{m i n})\end{array}$ & $\begin{array}{c}\text { Omax } \\
(\mathbf{M P a})\end{array}$ & $\begin{array}{c}\text { Std } \\
\text { Dev }\end{array}$ & $\begin{array}{c}\text { Kappa } \\
\text { no. }\end{array}$ \\
\hline 1 & $10 \%$ & 160 & 15 & 664 & 208 & 5.43 \\
2 & $10 \%$ & 160 & 45 & 677 & 187 & 4.09 \\
3 & $10 \%$ & 180 & 15 & 449 & 121 & 3.58 \\
4 & $15 \%$ & 160 & 15 & 632 & 185 & 5.12 \\
5 & $15 \%$ & 160 & 45 & 532 & 137 & 2.80 \\
6 & $15 \%$ & 180 & 15 & 280 & 101 & 2.44 \\
control & - & - & - & 607 & 210 & - \\
\hline
\end{tabular}


Table 2. Crystallinity index of $\mathrm{NaOH}$ treated and untreated hemp fibre

\begin{tabular}{|c|c|c|c|}
\hline & $I_{a m}\left(2 \theta=18.1^{\circ}\right)$ & $I_{002}\left(2 \theta=22.5^{0}\right)$ & Crystallinity Index (\%) \\
\hline $\begin{array}{l}\mathrm{NaOH} \text { Treated Hemp } \\
\text { (Treatment no.2) }\end{array}$ & 103 & 1684 & 93.9 \\
\hline Untreated Hemp & 94 & 764 & 83.7 \\
\hline
\end{tabular}


Table 3. Summary of composite tensile strengths (MPa).

\begin{tabular}{|c|c|c|c|c|c|c|c|c|c|c|}
\hline \multirow{3}{*}{$\begin{array}{l}\text { MAPP content } \\
(w t \%)\end{array}$} & \multirow{3}{*}{ Origin of hemp } & \multirow{3}{*}{$\begin{array}{l}\text { Hemp fibre } \\
\text { length }\end{array}$} & \multicolumn{8}{|c|}{ Hemp fibre content } \\
\hline & & & \multicolumn{2}{|c|}{$0 \%$} & \multicolumn{2}{|c|}{$30 \%$} & \multicolumn{2}{|c|}{$40 \%$} & \multicolumn{2}{|c|}{$50 \%$} \\
\hline & & & $\sigma$ & s.dev & $\sigma$ & s.dev & $\sigma$ & s.dev & $\sigma$ & s.dev \\
\hline 0 & Hawkes-Bay & Short & 22.8 & 0.1 & 25.9 & 0.7 & 28.1 & 0.7 & & \\
\hline 1 & Hawkes-Bay & Short & 24.2 & 0.4 & 29.7 & 0.7 & 34.7 & 0.2 & & \\
\hline 2 & Hawkes-Bay & Short & 24.0 & 0.2 & 36.7 & 0.7 & 37.6 & 1.3 & $35.6^{B}$ & 0.4 \\
\hline 2 & Hawkes-Bay & Long & & & & & 39.1 & 2.8 & & \\
\hline 2 & Waikato & Long & & & & & $38.3^{A}$ & 2.8 & & \\
\hline 3 & Hawkes-Bay & Short & & & & & 47.2 & 1.1 & $43.9^{B}$ & 3.0 \\
\hline 3 & Hawkes-Bay & Long & & & & & & & $41.1^{\mathrm{B}}$ & 1.4 \\
\hline
\end{tabular}

${ }^{\mathrm{A}}$ only 4 successful tests were conducted

${ }^{\mathrm{B}}$ processing temperature was increased to from $180^{\circ} \mathrm{C}$ to $190^{\circ} \mathrm{C}$ 
Table 4. Summary of composite Young’s moduli (GPa).

\begin{tabular}{|c|c|c|c|c|c|c|c|c|c|c|}
\hline \multirow{3}{*}{$\begin{array}{l}\text { MAPP content } \\
\text { (wt\%) }\end{array}$} & \multirow{3}{*}{ Origin of hemp } & \multirow{3}{*}{$\begin{array}{l}\text { Hemp fibre } \\
\text { length }\end{array}$} & \multicolumn{8}{|c|}{ Hemp fibre content (wt\%) } \\
\hline & & & \multicolumn{2}{|c|}{0} & \multicolumn{2}{|c|}{30} & \multicolumn{2}{|c|}{40} & \multicolumn{2}{|c|}{50} \\
\hline & & & $\mathbf{E}$ & s.dev & $\mathbf{E}$ & s.dev & $\mathbf{E}$ & s.dev & $\mathbf{E}$ & s.dev \\
\hline 0 & Hawkes-Bay & Short & 1.07 & 0.03 & 2.43 & 0.11 & 3.72 & 0.20 & & \\
\hline 1 & Hawkes-Bay & Short & 1.15 & 0.04 & 2.95 & 0.13 & 3.94 & 0.20 & & \\
\hline 2 & Hawkes-Bay & Short & 1.11 & 0.03 & 2.93 & 0.10 & 4.02 & 0.33 & $5.93^{B}$ & 0.78 \\
\hline 2 & Hawkes-Bay & Long & & & & & 4.38 & 0.35 & & \\
\hline 2 & Waikato & Long & & & & & $4.10^{\mathrm{A}}$ & 0.42 & & \\
\hline 3 & Hawkes-Bay & Short & & & & & 4.88 & 0.38 & $6.76^{\mathrm{B}}$ & 1.83 \\
\hline 3 & Hawkes-Bay & Long & & & & & & & $5.37^{\mathrm{B}}$ & 0.78 \\
\hline
\end{tabular}

A only 4 successful tests were conducted

${ }^{\mathrm{B}}$ processing temperature was increased to from $180^{\circ} \mathrm{C}$ to $190^{\circ} \mathrm{C}$ 


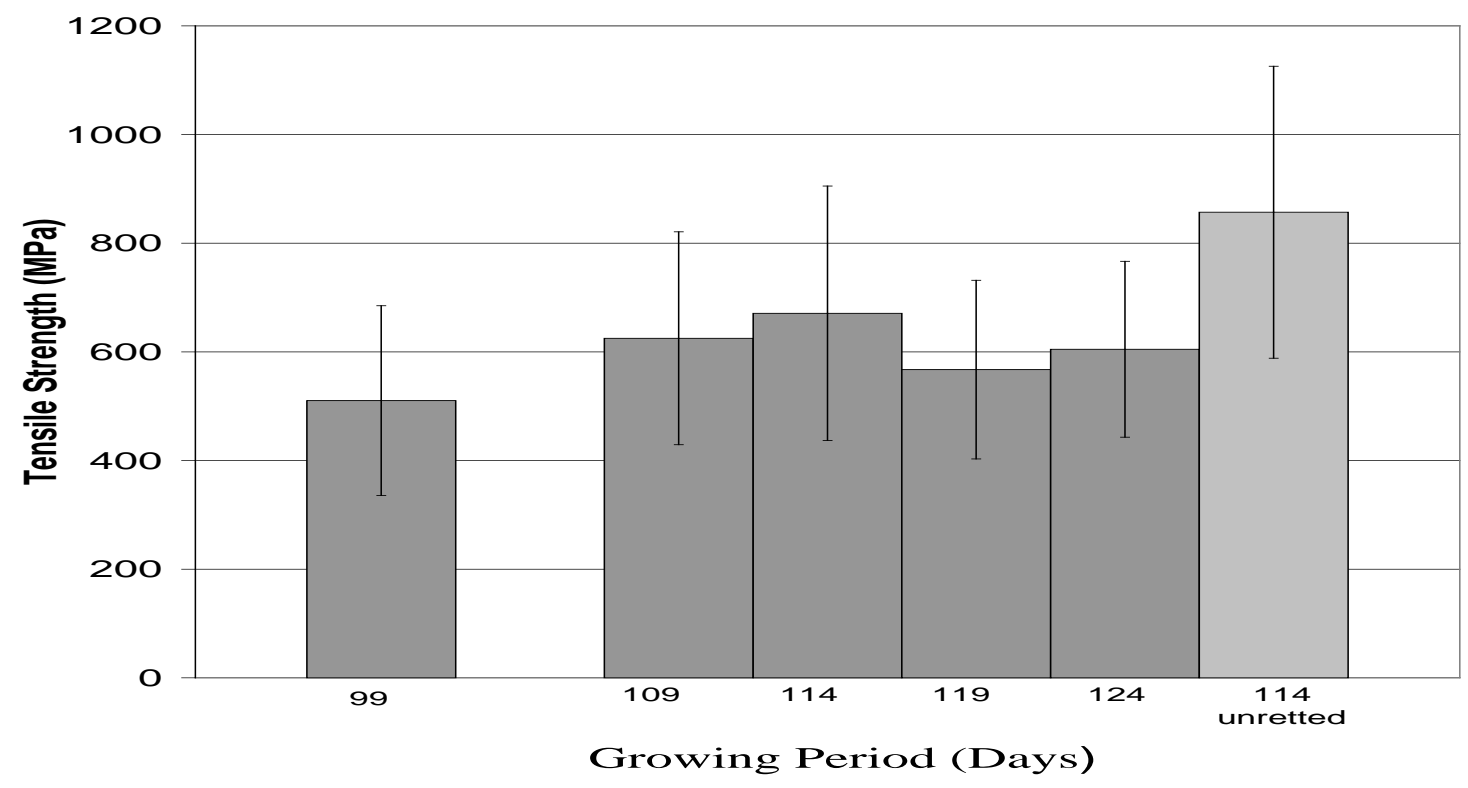

Figure 1. The average tensile strength of single hemp fibres over a range of growing periods. All fibres were retted unless otherwise stated. 


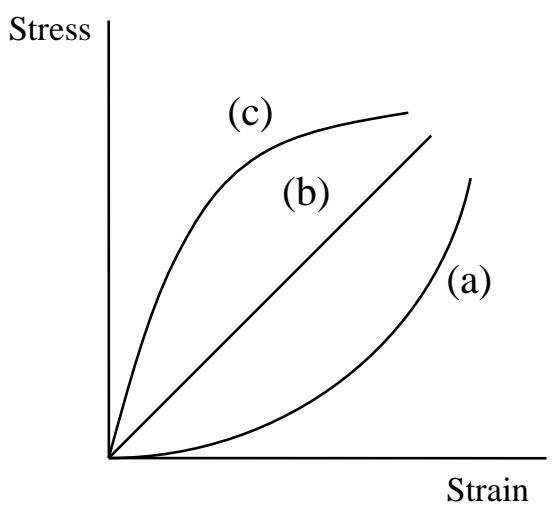

Figure 2. Typical stress-strain curves for hemp fibres. 


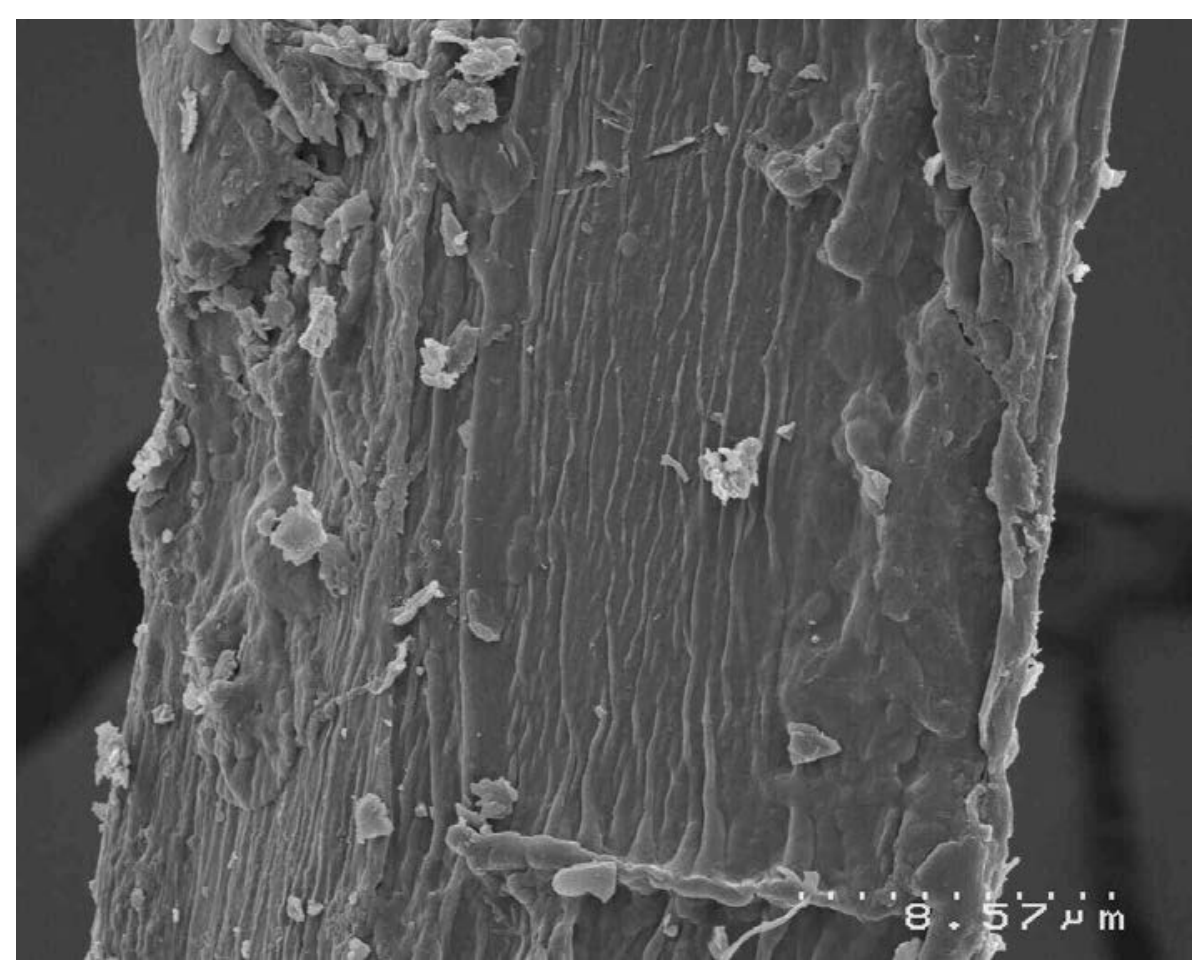

Figure 3(a). SEM of untreated hemp fibre surface.

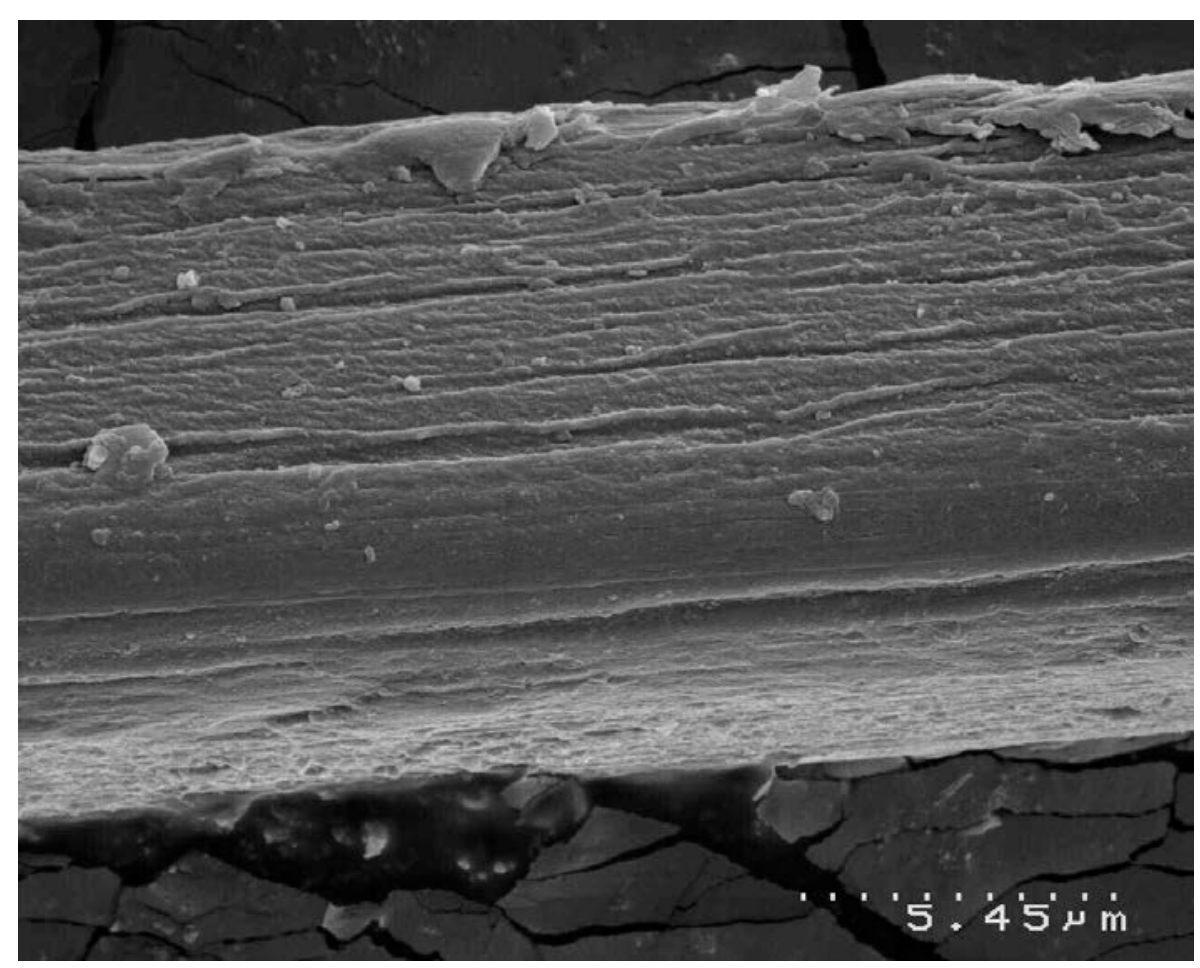

Figure 3(b). SEM of alkali treated hemp fibre surface. 


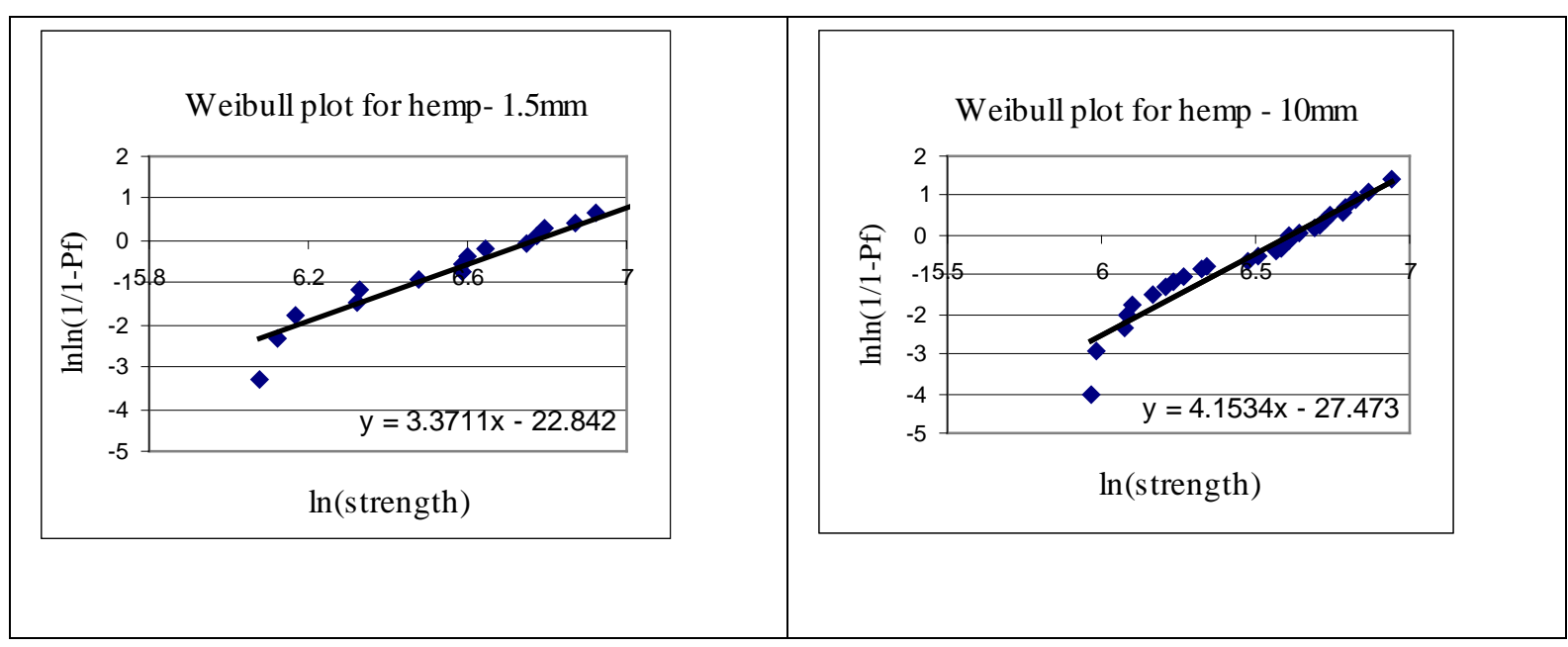

Figure 4. Weibull plots for hemp tested at $1.5 \mathrm{~mm}$ and $10 \mathrm{~mm}$ gauge lengths. 


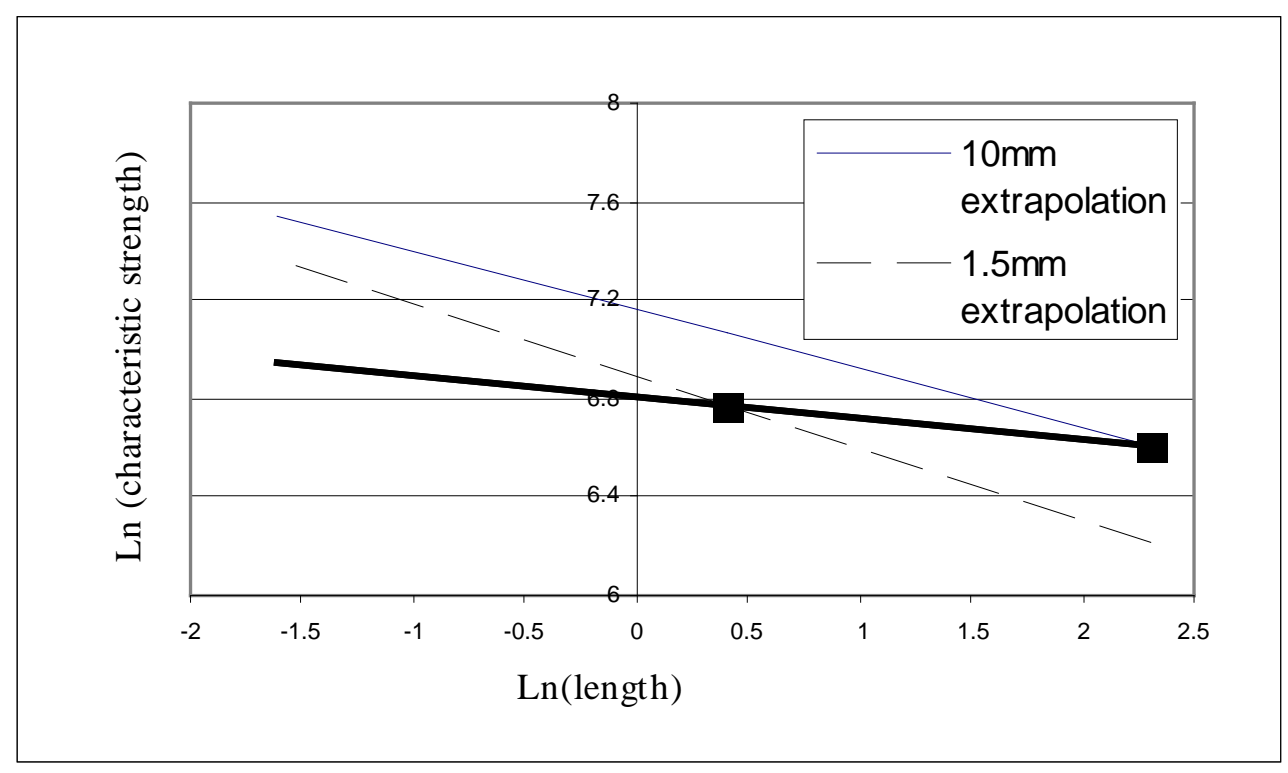

Figure 5. Weak link scaling plot showing extrapolated predictions from values at 1.5 and $10 \mathrm{~mm}$ gauge lengths. 


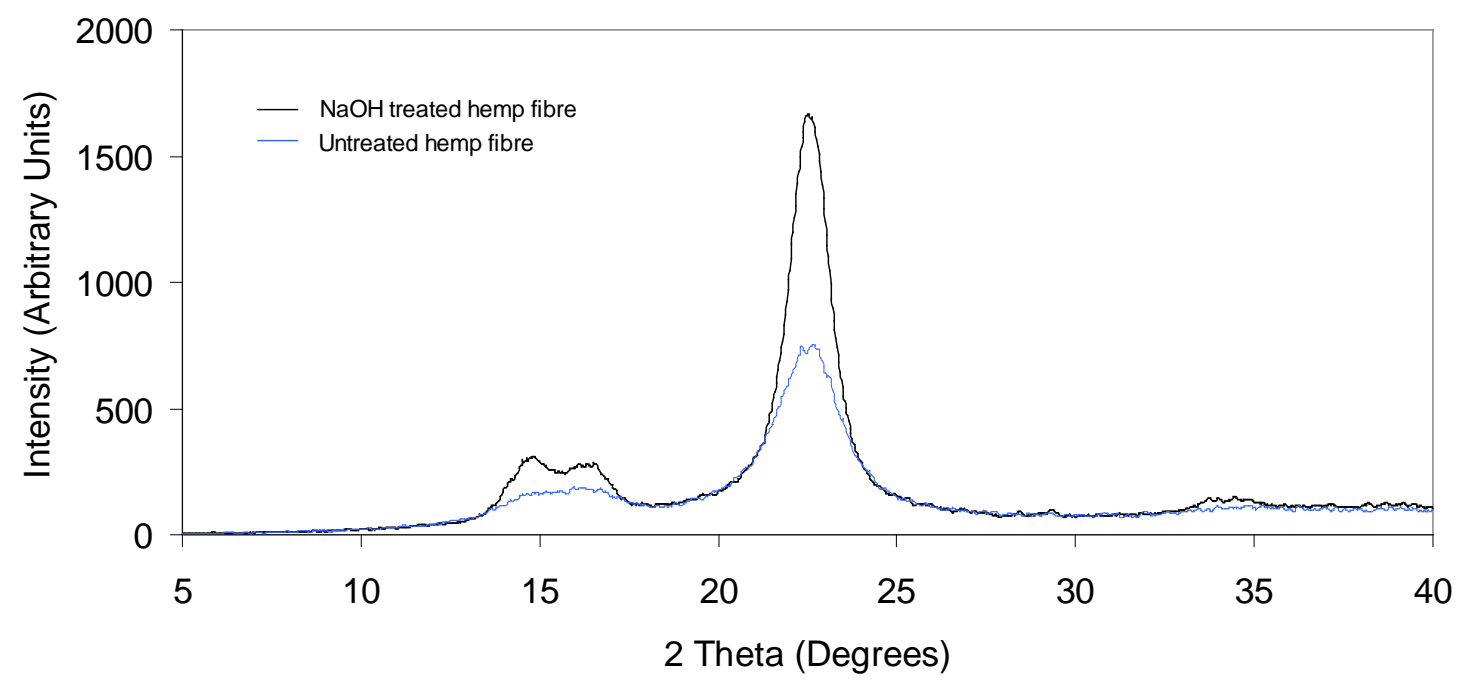

Figure 6. X-Ray diffraction patterns of $\mathrm{NaOH}$ treated and untreated hemp fibre. 